The LITA Governing Board has had a productive autumn, and I wanted to share a few highlights. Keeping an eye on how better to understand and improve the member experience, we have a couple of new groups getting down to work.

\title{
LITA Local Task Force
}

I'm writing this shortly after returning from LITA Forum 2015, which was a fantastic meeting. I'm glad that so many people were able to attend, and I hope even more will come to Forum 2016. But we know many members cannot regularly travel to national meetings, and even the best online experience can lack the serendipitous benefits that so often come from face-to-face meetings.

The new LITA Local Task Force will be responsible for creating a toolkit to facilitate local groups' ability to host events, including information on event planning, accessibility, and ensuring an inclusive culture at meetings. So you'll be able to host a LITA event in your own backyard! (If your backyard has a couple of meeting rooms and good wireless.)

\section{Forum Assessment and Alternatives Task Force}

As we begin work on LITA Local events, we are also turning our eyes to our national meeting. Planning the next LITA Forum is essentially a year-round process. We assess the work we've done on previous forums, of course, but the annual schedule often doesn't afford an opportunity to strategically rethink what Forum is and how it can best serve the members. To address that issue, we're convening another new task force, on Forum Assessment and Alternatives.

This group will look critically at how Forum advances our strategic priorities, and will also look at other library technology conferences to help identify how Forum can continue to distinguish itself in a rapidly changing environment.

\section{LITA Personas Task Force}

Finally, as I write this, the board is in the final stages of creating a Personas Task Force as a tool for better understanding our current and potential new members. A well-constructed set of personas, representing both people who are LITA members and people who aren't-but who could be or should be-will become a valuable tool for membership development, programming, communications, assessment, and other purposes.

Each of these task forces will work throughout 2016 and deliver their results by Midwinter 2017. It is worth noting that we could only convene these groups because we have a strong list of volunteers on tap. If you haven't filled out a LITA volunteer form recently, please considering doing so at http://www.ala.org/lita/about/committees.

Thomas Dowling (dowlintp@wfu.edu) is LITA President 2015-16 and Director of Technologies, Z. Smith Reynolds Library, Wake Forest University, Winston-Salem, North Carolina. 